\title{
18
}

\section{Emissions and economic development Must China choose?}

\section{Peter Sheehan and Fiona Sun}

China's energy use has surged since the turn of the century, almost doubling between 2000 and 2007. The rate of growth in energy use during this period (9.2 per cent per annum) has been more than twice that of the previous two decades (4.5 per cent), in spite of similar rates of economic growth. Many factors were undoubtedly responsible for this sharp change in trend. One was the post-2001 development pattern, with a focus on heavy industry, exports and fixed-asset investment. Another was the fundamental change in the structure, ownership and operation of the energy industry that took place during the 1990s, which rendered the controls of the planned economy no longer applicable. These and other factors on the demand side were supported by a massive expansion of energy supply, with electricity-generation capacity, for example, more than doubling in the period.

The scale of this energy use, and of the industrial and infrastructure investment associated with it, is now such as to have major ramifications within China and globally. Internally, the environmental and social costs of heavy industry, construction and fossil-fuel use have become onerous, and a major concern of the Chinese people. As a result, a central priority in the eleventh Five-Year Plan (2006-10) is to change the pattern of development and to reduce energy use per unit of gross domestic product (GDP) by 20 per cent. Greenhouse gas emissions from China are also now of major significance for the global climate: in spite of its low per capita emissions, China has now passed the United States as the largest emitter of carbon dioxide, and these 
emissions continue to rise rapidly. If present trends continue, China's annual greenhouse gas emissions by 2030 could be comparable with total global emissions in 2000.

There can be no dispute that the current atmospheric concentration of greenhouse gases is due mainly to the past activities of the industrialised countries, and that they have the prime responsibility for addressing this problem. The scale of China's fossil-fuel use, however, and of its emissions, is now such that no solution to global warming can be found without the active involvement of China. More specifically, it is now clear that, if rapid global warming imposing severe damage on many communities is to be avoided, global emissions must peak within the next one to two decades at least, and then decline. The scale of China's activities now means that, even given an urgent response by the industrialised world, China's emissions must also peak and then begin to fall within the foreseeable future.

Here the issue that China faces, along with other developing countries, is often put in terms of a choice between economic development and emissions. In spite of rapid growth, the bulk of China's population remains poor, with average GDP per capita in China still at only 15 per cent of Organisation for Economic Cooperation and Development (OECD) levels in 2005, according to the new International Comparison Program estimates at purchasing power parity prices (World Bank 2007). With increasing energy use seen as essential to growth, and with coal forming the majority of China's energy resources, it is argued that China can stabilise emissions within, say, 25-30 years only at the cost of sharply slowing growth, and hence giving up on its historical goal of lifting its people out of poverty.

This chapter addresses the question: does China have to choose between rapid economic growth and stabilising emissions? This question is posed with regard to the priority being given in the eleventh Five-Year Plan to the reduction of energy use per unit of output, and more generally to the Chinese government's strong enunciation of the need to move to a new development model-one that is socially and environmentally sustainable and that contributes to maintaining a harmonious society. Could such a new model, with the many policy initiatives that it contains, be consistent with continued rapid growth and a stabilisation of greenhouse gas emissions?

To build a basis for providing a tentative answer to this question, we undertake three tasks in the next three sections: we review China's energy use and emissions in recent decades, with special reference to the break in the trend about 2001; we discuss the new development model and some of its 
implications; and we outline the scoping model that will be used to project and analyse China's future emissions. We then use this simple model to estimate the potential impact on energy use and carbon dioxide emissions to 2030 from interventions in six policy areas consistent with the new development model, with conclusions presented in the final section.

\section{China's energy use and carbon dioxide emissions, 1979-2007}

As noted above, the explosive growth in energy use after 2001 was in sharp contrast with earlier trends. From the 'opening to the market' in 1979 to 2001, energy use grew at a much lower rate than GDP, with average rates of growth of 4.1 per cent and 9.7 per cent for energy use and GDP, respectively, implying that the energy intensity of China's GDP fell continuously through to 2001 and the elasticity of energy use with respect to GDP was less than 0.5 on average for the period (Figure 18.1). This decline in reported energy intensity was especially marked in the second half of the 1990s, so that the shift to rates of growth in energy use in excess of GDP growth after 2001 had profound and unexpected implications in energy markets, and led to severe shortages in 2003 and subsequent years. This apparent structural shift in the relationship between GDP growth and energy use in China raises serious questions in several areas. For example, is this a temporary aberration or a fundamental structural shift and, if so, what caused it? What basis should we use to interpret China's likely future energy demand on existing policies? What policies are likely to be most effective in reducing the rate of growth of China's demand for energy, in the light of this shift?

There is an extensive literature on the reasons for the low income elasticity of energy use in China during 1979-2001, and hence the rapidly declining overall energy intensity. This literature is reviewed in Sheehan and Sun (2007). Much of the debate has been about the relative roles of structural change in the pattern of output and energy demand and of changes in energy intensity within sectors in explaining China's energy use. Although some earlier studies emphasised structural change, all of the empirical studies from Huang (1993) onwards found a major role for reduced energy intensities at the sectoral level. In terms of structural effects, the results are much more mixed, with some studies finding negative effects of structural change on overall energy intensity but others (such as Lin and Polenske 1995; Garbaccio et al. 1999) finding positive effects. Overall, it seems clear that widespread declines in energy intensity rather than a shift in the pattern of growth to less-intensive sectors was the main factor driving the fall in overall energy intensity during 1979-2001. 
The reasons for the increased energy efficiency within sectors in China in this period are another matter. Three main reasons have been given in the literature for these sectoral effects: the impact of rationing and energy conservation programs in a planned economy with an initially high level of energy use and limited growth in energy supplies; the impact of technology, broadly defined, on energy use; and the impact of higher energy prices on the demand for energy (Sinton and Levine 1994; Sinton et al. 1998; Andrews-Speed 2004; Lin 2005). Our interpretation of the literature therefore is that, during the 1980s, the fall in sectoral intensities is to be ascribed to a combination of energy conservation programs and technological change being driven by a planned economy with energy rationing (Sheehan and Sun 2007). In the 1990s, those factors continued to be of importance, while rising relative energy prices also began to play a significant role as the economy was freed up. The literature does not give an unequivocal answer to the question about the role played by structural change in reinforcing or partially offsetting these declining sectoral intensities.

Figure 18.1 Energy intensity and the energy elasticity of GDP in China, 1979-2006

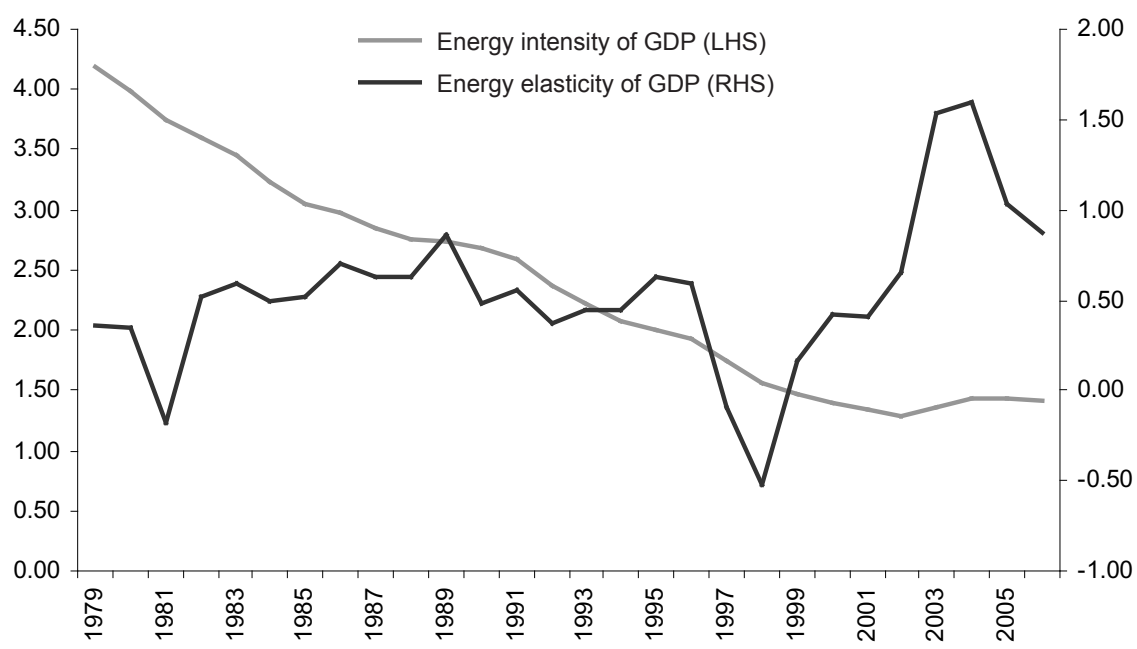

Note: Energy intensity is measured in terms of units of energy use (in hundred thousand tonnes of standard coal equivalent) per unit of GDP (in billion yuan in 2000 values).

Source: National Bureau of Statistics (NBS), 2007. China Statistical Yearbook 2007, China Statistics Press, Beijing. 
It is likely therefore that several interrelated factors are responsible for the widespread fall in sectoral energy intensities in the first two decades of rapid economic growth in China: a combination of energy rationing and strong energy conservation programs in a planned economy with limited energy supplies; continuing technological upgrading, in part spurred by these circumstances; and, in the 1990s, the impact of rising relative prices for energy. By the end of the 1990s, however, fundamental changes in the structure, ownership and operation of Chinese industry, including in the energy sector, had taken place, so that the mechanisms of the planned economy were no longer relevant. Energy use per unit of GDP reduced by two-thirds between 1980 and 2000, and much technological upgrading took place. Without the control mechanisms of the planned economy, however, further major reductions in energy intensity could be achieved only by market forces and by strong policy initiatives. There are many reasons why, in developing countries, energy is normally a superior good, ${ }^{1}$ as the development process shifts the pattern of production and of lifestyles towards more energy-intensive activities and products. Beyond the command economy, strong market and policy effects would be needed in China to offset this development effect.

In the aftermath of China's entry to the World Trade Organization (WTO) in 2001, demand for China's products was very strong, the supply of energy increased rapidly and the policy focus on energy efficiency was limited. With structural effects contributing to rising energy use and the command-economy mechanisms generating falling sectoral intensities no longer operational, it is not surprising that an aggregate energy intensity of 1 or more re-emerged. This analysis implies that, going ahead, there is no reason to expect a return to an aggregate energy elasticity of $0.5-0.6$ to occur 'naturally'; achieving an aggregate elasticity well below 1 will be hard won by sustained policy initiatives, especially while structural change continues to contribute to increased energy use.

\section{The development strategy in the eleventh Five-Year Plan}

While fully recognising the remarkable achievements of nearly three decades of rapid growth, it is acknowledged widely within China that some adjustment of the current development strategy is necessary. In his March 2006 Report on the Work of the Government, Premier Wen Jiabao said of the issues arising from the tenth Five-Year Plan period (2001-05):

The main problems were an unbalanced economic structure, weak capacity for independent innovation, slow change in the pattern of economic growth, 
excessive consumption of energy and resources, worsening environmental pollution, serious unemployment, imbalance between investment and consumption, widening gaps in development between urban and rural areas and between regions, growing disparities between certain income groups, and inadequate development of social programs. We need to work hard to solve all these problems. (Wen 2006)

The eleventh Five-Year Plan outlined a vision of development that was socially and environmentally sustainable and that contributed to maintaining a harmonious society, and outlined programs to be implemented to address these issues and to achieve such a form of development. As one observer (Naughton 2006) wrote, the proposals in China's eleventh Five-Year Plan for the period 2006-10 were striking:

There emerges from this Plan document a rich and comprehensive vision of a sustainable development process in China, and a glimpse of the kind of government role that would be required by this development process. The vision is of a society that is more creative, more focused on human resource development, and treads with a lighter and more environmentally benign step.

It is one thing to outline a vision of a sustainable economy and a harmonious society and quite another to define and implement a detailed set of programs to give effect to this vision. This is especially so in such a diverse, vibrant and internationally engaged society as contemporary China. The forces shaping the current growth pattern-from the role of local governments and the limited power of the central government, the strong influence of foreign companies and investors and the level of the exchange rate to the popular desire for a strong China and a better life-are complex and interrelated, and it will take a major effort to realign them.

Achieving this vision will require sustained and effective delivery of new policies in many different areas, especially given the momentum that has built up behind the current development strategy since China's entry into the WTO. For example, four important objectives of current government policy are:

- to make growth more sustainable and environmentally benign, to reduce the rate of energy and water use and reduce pollution

- to increase innovation within all sectors, including industry, and to shift the pattern of activity from low value-added output based on low labour costs towards higher value-added activities based on knowledge 
- to change the structure of growth towards the service sector, and to accelerate the growth of particular service sectors that contribute directly to individual welfare

- to improve the position of people in the countryside, and to build structures to ensure that the benefits of growth also flow to people in rural areas and those regions that are lagging.

Achievement of each of these objectives would contribute, directly or indirectly, to reduced energy use and to environmental sustainability. This is particularly true of the intention to shift the pattern of economic activity from energy-intensive areas (such as specific forms of heavy industry) to industry and service sectors that are knowledge intensive and rely less on energy and other resource inputs; and to stimulate the adoption of advanced technologies, processes and practices that are energy efficient and more environmentally benign.

The attempt to change substantially the structure and technological base of a large, rapidly growing economy is without precedent and is likely to prove difficult, especially in a country still dealing with the transition from a planned to a market economy. Our question here is whether there are implementation paths within this general approach that could enable China to continue rapid growth while also stabilising emissions within 25-30 years.

\section{A scoping model for China's energy use and carbon dioxide emissions}

The analysis here is based on what we refer to as a scoping model: a simple modelling framework in which the key relationships and assumptions are spelled out so that the results are highly transparent. There is a wide range of global energy or integrated assessment models that now include China, as well as a number of models applied specifically to China. These more complex models have many theoretical advantages over such simple models, but require estimation of, or assumptions about, a large number of parameters, such as price and income elasticities of demand, elasticities of substitution, supply curves and the rate and structure of economic growth. The evidence available for many of these parameters is very limited in China, not only because of limited data but because of the sharp changes that have taken place in economic institutions and in the structure of the energy sector in the past decade. For example, for much of the period since the opening to the market in 1979, energy use was supply constrained; this means that there are difficulties in obtaining reasonable estimates of various demand elasticities. 
The swings in the aggregate income elasticity of energy use discussed above also illustrate the level of uncertainty that prevails in this area, as well as the need to incorporate recent trends.

In such a situation, the use of a large, complex model might require heroic assumptions and disguise the key uncertainties, leading to either misleading or non-transparent results. Complex models also require more detailed data, which are often assembled only with long time lags. Sheehan (forthcoming) reviews the base cases in simulations with a wide range of integrated assessment models: those participating in the Energy Modelling Forum (EMF 21) modelling comparison project (Weyant et al. 2006) and the three models used in the Synthesis and Assessment Product 2.1a of the US Climate Change Science Program (CCSP) (Clarke et al. 2007). Sheehan found that none of the 10 models in the EMF 21 exercise that provided data on China and India or the three models used in the CCSP report provided a realistic assessment of recent and emerging trends in these two countries.

For the April 2008 edition of the World Economic Outlook, the International Monetary Fund (IMF) used the G-cubed model to analyse global emission trends and policy responses (IMF 2008), with surprising results. The baseline scenario shows global energy-related carbon dioxide emissions stagnating between 2002 and 2010 (a growth of only 0.5 per cent per annum), but then growing rapidly between 2010 and 2030 (3.1 per cent per annum). For China, the annual growth rates of emissions for these two periods are 1.8 per cent and 6 per cent, while for Non-Annex 1 countries as a whole the growth rates are 0.2 per cent and 5.1 per cent (IMF 2008:Table 4.4). In fact, we know that emissions in developing countries have surged since about 2001, especially in China, where the growth in energy use and energy-related carbon dioxide emissions for 2002-10 will be about 10 per cent per annum. The IMF figure for China in 2010 (3.8 giga-tonnes of carbon dioxide) is therefore less than half the likely outcome, given trends through to 2008. If global and Chinese emissions had stabilised since 2002, rather than surged, the international climate debate now would be much different. On the other hand, if the IMF's predicted baseline growth for 2010-30 is added to the real experience of this decade, the global problem will be dire indeed. These issues again illustrate the problems involved in using large models to analyse complex, rapidly changing situations about which there is limited knowledge. 


\section{A simple scoping model}

Studies of the demand for energy frequently use a standard framework such as:

$$
\mathrm{E}_{i t}=\mathrm{f}\left(\mathrm{Y}_{i t}, \mathrm{P}_{i t}, \mathrm{Z}_{i t}\right)
$$

in which $\mathrm{E}_{i t}$ is the demand for energy in industry sector $i$ in period $t, \mathrm{Y}_{i t}$ is an income or output variable relevant to sector $i, \mathrm{P}_{i t}$ is the relative price of energy in sector $i$ in period $t$, and $Z_{i t}$ is a vector of other variables affecting energy demand in sector $i$, such as technological change and government policy initiatives related to energy conservation. Assuming that from 2006 onwards supply constraints on energy demand in China have been removed, so that real energy use can be treated as demand determined, we use this framework to construct the projection model for China, applying it to 11 sectors. In a loglinear specification, Equation 1 becomes

$$
\operatorname{Ln}\left(\mathrm{E}_{i t}\right)=\alpha_{i t} \ln \mathrm{Y}_{i t}+\beta_{i t} \ln \mathrm{P}_{i t}+\gamma_{i t} \ln \mathrm{Z}_{i}
$$

in which $\alpha_{i t} \beta_{i t}$ and $\gamma_{i t}$ are the elasticities of energy use with respect to $\mathrm{Y}, \mathrm{P}$ and $Z$, respectively. Partial differentiation of Equation 2 with respect to time and rearrangement gives

$$
\delta \mathrm{E}_{i t}=\alpha_{i t} \delta \mathrm{Y}_{i t}+\beta_{i t} \delta \mathrm{P}_{i t}+\gamma_{i t} \delta \mathrm{Z}_{i t}
$$

in which in the projection model the change variables ( $\delta \mathrm{E}$ and so on) represent rates of change with respect to time.

To enable examination of issues concerning the impact of the pattern of growth on energy use, we define two new elasticities relating the rate of growth of value added in sector $i$ in period $t$ to the growth rate of a higher-level variable, $\mathrm{A}_{i t}$; the ratio of the growth rate of value added in aggregate sector $i$ in period $t$ to growth in total GDP in that period; and $\mathrm{I}_{i t^{\prime}}$, the ratio of the growth rate of value added in industry sector $i$ in period $t$ to growth in total industry value added in that period (for the six sectors within industry). Therefore, $\mathrm{A}_{i t}$ defines the pattern of growth across six aggregate sectors (in which industry is a single sector) for a given rate of growth of aggregate GDP, and $\mathrm{I}_{i t}$ defines the pattern of growth across the six industry sectors for a given rate of growth of industry value added. That is

$$
\delta \mathrm{Y}_{i t}=\delta \mathrm{Y}_{t} \mathrm{~A}_{i t} \mathrm{I}_{i t}
$$


in which $\mathrm{A}_{i t}$ takes a value of 1 if $i$ is a disaggregated industry sector and $\mathrm{I}_{i t}$ takes a value of 1 if $i$ is an aggregate sector.

Substituting Equation 4 into Equation 3 and converting growth rates into levels, gives the following expression for total energy use in China in sector $i$ in period $t$

$$
\mathrm{E}_{i t}=\mathrm{E}_{i t-I}\left(1+\alpha_{i t} \delta \mathrm{Y}_{t} \mathrm{~A}_{i t} \mathrm{I}_{i t}+\beta_{i t} \delta \mathrm{P}_{i t}+\gamma_{i t} \delta \mathrm{Z}_{i t}\right)
$$

Energy use involves different types of fuels (coal, oil, natural gas and various types of non-fossil and renewable fuels), and each of the fossil fuels has a different propensity to generate carbon dioxide emissions. The share of fuel type $j$ in total energy use in sector $i\left(\mathrm{~s}_{i j}\right)$ will vary over time, depending on availability, relative prices, investment patterns, policy initiatives and other factors. The energy use met by fuel $j$ in year $t$ in sector $i$ can be denoted by $\mathrm{E}_{i j t}$ $=\mathrm{E}_{i t} \cdot \mathrm{s}_{i j t}$, and total use of fuel $j$ will be given by

$$
\mathrm{E}_{j t}=\sum s_{i j t} \mathrm{E}_{i t-1}\left(1+\alpha_{i t} \delta \mathrm{Y}_{t} \mathrm{~A}_{i t} \mathrm{I}_{i t}+\beta_{i t} \delta \mathrm{P}_{i t}+\gamma_{i t} \delta \mathrm{Z}_{i t}\right)
$$

Finally, carbon dioxide emissions per unit of use of fuel $j\left(\mathrm{~m}_{j t}\right)$ in China will also vary over time, depending, for example, on the quality of fuel used and the technological processes involved. Total carbon dioxide emissions from the use of fuel $j$ in year $t$ will then be given by

$$
\mathrm{M}_{j t}=m_{j t} \mathrm{E}_{j t}=m_{j t} \mathrm{E}_{j t}
$$

with total emissions given by summing over fossil-fuel types. This simple model is used below to analyse and project China's future energy use and carbon dioxide emissions from energy use, given suitable projections or assumptions for the many parameters involved.

\section{Data and the industrial structure of China's energy use}

The data for the analysis are drawn from official Chinese statistics (from successive editions of the China Statistical Yearbook; NBS various years) and from the International Energy Agency (IEA) database and from the World Energy Outlook 2007 (IEA 2007). Data for energy use and value added are taken from, or derived from, the China Statistical Yearbook (NBS various years), while data for fuel use by industry and emissions intensity are sourced from the IEA. Some issues arise in integrating the two data sources: for example, in terms of the 
different treatment of renewable energy sources. Further information on the issues involved in assembling and using these data can be found in Sheehan and Sun (2007).

As noted above, issues concerning the structure of energy demand are at the heart of the Chinese debate, and Table 18.1 provides some key statistics on China's energy use. Energy use is concentrated heavily in five industries: petroleum processing, chemicals, non-metallic minerals, ferrous metals and non-ferrous metals. These industries together have energy use per unit of value added more than four times the national average, and nearly six times that of all other industries. In 2006, these industries accounted for 44 per cent of national energy use but only 10 per cent of GDP. During 2001-06, real value added in this group grew by 15.2 per cent per annum, compared with the national rate of 10.2 per cent, and energy use grew by 15.7 per cent per annum, given an elasticity of 1.04. The five energy-intensive industries accounted for 54.8 per cent of the increase in total energy use, while providing only 13.6 per cent of the increase in China's GDP during this period.

Given the concentration of energy use in these industries, they are critical to the analysis, and reducing the rate of growth of these industries and their energy intensity is a key priority for government policy. On the other hand, the role of the services sector cannot be neglected. As Table 18.1 also shows, total energy use in services grew by 10.2 per cent during 2001-06-in line with the growth in value added-while the energy intensity of the transport sector was high and its energy use grew rapidly.

\section{Policy intervention areas and simulation cases}

The analysis undertaken below makes use of a base or unchanged policy case, and three alternative policy cases. In view of the adoption of the target of a 20 per cent reduction in aggregate energy intensity in the eleventh Five-Year Plan, the policy environment in China has been in flux in 2006 and 2007; new initiatives implemented in these years are included in the policy options cases. The policy stance in 2005 is interpreted as one of continued but modest efforts to contain energy use and carbon dioxide emissions from fuel use, through the introduction of market mechanisms, increased energy prices and programs to encourage energy conservation and the use of advanced technologies. These policies are incorporated in the base case.

In shaping these cases, six policy intervention areas are employed, and are included in the model

- the rate of growth in value added in industry relative to that of overall GDP

- the industry composition of the growth in industrial output 


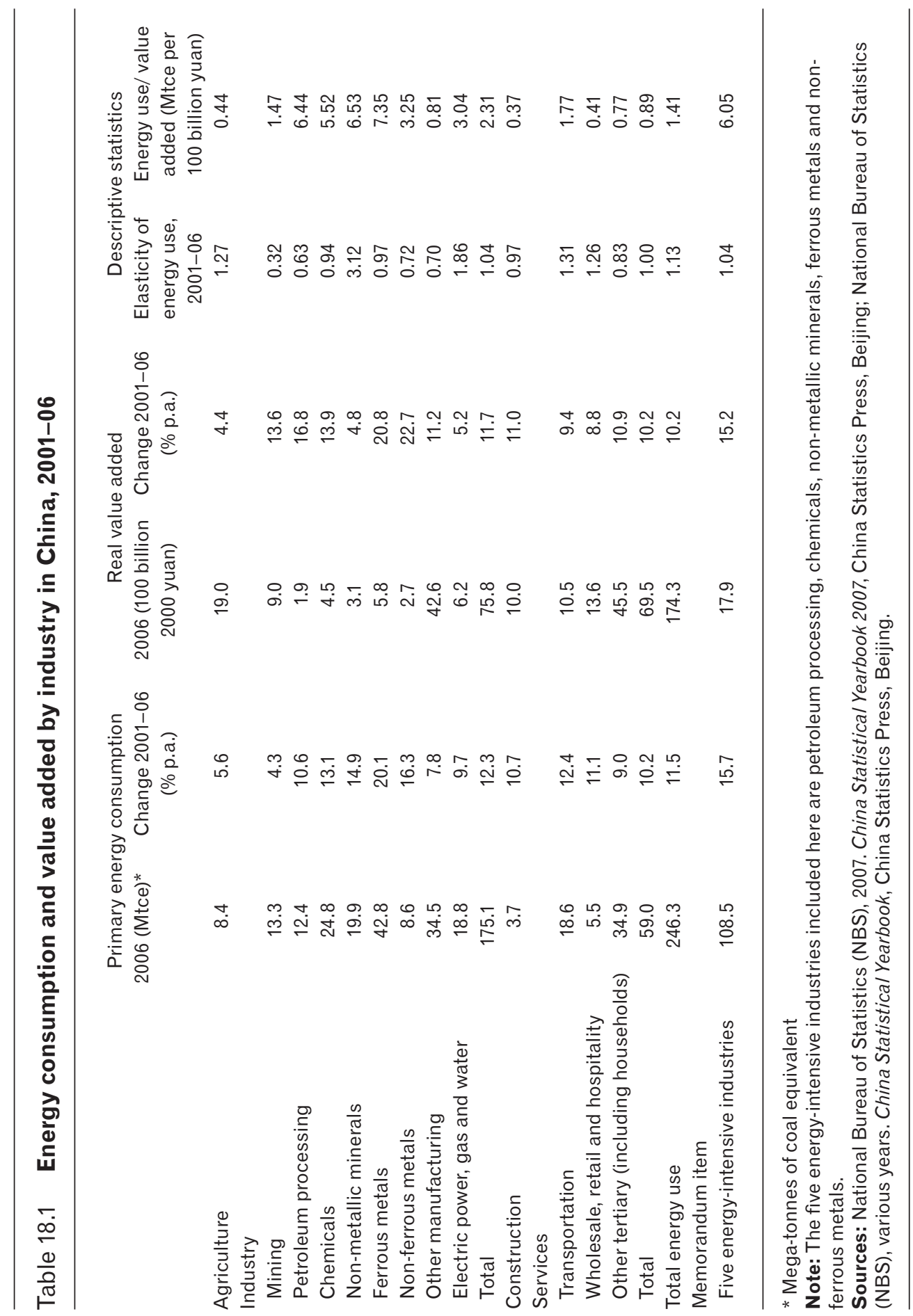


- the rate of growth of energy prices relative to general output prices

- the reduction in energy use from programs to promote energy conservation and the adoption of new technologies

- the composition of energy supply by fuel

- the emissions intensity of the use of various fossil fuels.

We distinguish these policy intervention areas from the specific policy instruments (such as export tariffs, energy taxes, research and development subsidies or changes in relative prices) that might be used to achieve a given policy objective in a given area. Policy instruments are not addressed here, but the Chinese government is currently taking some action in each of these areas, some examples of which are provided below.

In taking action to achieve the eleventh Five-Year Plan's goal of reduced energy intensity, the government has relied mainly on 'command and control' measures, rather than price or tax measures, and has in part reverted to tried and true methods that were successful in very different circumstances before 1995. A number of measures have been taken to curtail the growth of energyintensive industries, and the 'Top-1,000 Energy Consumers Enterprise' program has been established to reduce energy use in large firms. In terms of structural change, initiatives have centred on the imposition of export tariffs, on the removal of support at all levels of government for energy-intensive industries, and on closing down inefficient capacity and on expanding service industries. Since 2004, the government has progressively removed its export incentives for energy and resource-intensive exports, and replaced them with export tariffs. Export tariffs on 142 such products were increased from 1 June 2007, with some moving from a 5 per cent to a 10 per cent tariff and others moving from 10 per cent to 15 per cent (MOF 2007). The central government has also issued a serious warning to local governments that all policies that encourage energy-intensive developments must cease (NDRC 2007), and it is entering into agreements with provincial governments to phase out inefficient capacity in energy-intensive industries. For iron and steel, for example, the objective is to close 100 million tonnes of inefficient iron production capacity by 2010 and 50 million tonnes of steel capacity; in mid 2007, an agreement with 10 provinces to close 40 million tonnes of iron capacity and 42 million tonnes of steel capacity was announced (Central Government Portal 2007). Finally, the State Council has announced plans to accelerate the development of the service sector, and to increase its share of GDP by 3 percentage points, and its share of employment by 4 percentage points, by 2010 . 


\section{Specification of the base and alternative policy cases}

The three alternative policy cases, which are cumulative in the sense that additional policy objectives are added in the second and third cases, are as follows.

- The new industrial structure case, in which the relative role of industry in total output and the role of energy-intensive industries in industrial output are reduced rapidly.

- The price and command measures case, in which, in addition to the structural changes, there is a more rapid increase in relative energy prices and more aggressive action to promote energy conservation and the use of new technologies.

- The additional measures case, in which further measures are taken to reduce energy use in transport and other services and to reduce the level of emissions per unit of fossil-fuel use.

The full set of assumptions and parameter specifications is provided in Table 18.2 and is described briefly below.

GDP growth rate. A common rapid growth path for GDP is used in all of the cases. GDP growth is assumed to moderate progressively from the current high levels to 8 per cent per annum by 2010 and to 7 per cent per annum by 2020, maintaining that level until 2030.

Underlying elasticities of energy use with respect to value added. For the critical issue of elasticities of energy use with respect to value added by industry, we specify a pattern of underlying elasticities that remains unchanged during the projection period, even though the real elasticities of energy use change as a result of the policies that are in force-in all cases. Consistent with the argument above, for the eleven industries we use the average elasticity value for the industry for 2001-06 as the underlying rate, with an upper bound of 1.2. The upper bound is used to ensure that unusually high elasticity values in particular cases during 2001-06 do not distort the long-run picture. Even using this specification, the overall projected elasticities of energy use with respect to GDP are much less than 1 in the longer term, falling to below 0.8 by 2030 in the base case and to 0.5 in the fullest policy case.

Relative prices for energy. While information on overall energy prices in China is limited, there seems to have been a significant increase in weighted average energy prices relative to the general price level in the 1990s and again in recent years, as higher global prices have flowed through to some extent to Chinese producers and consumers. On the basis of limited historical data, we assume an increase in average relative energy prices of 6 per cent per annum 
for each of the three years from 2006 to 2008 in all cases, with a further 3 per cent per annum in all subsequent years in the base case. For the second and third policy cases, we assume that a much more aggressive pricing stance is adopted in the longer term, with the 6 per cent increase in relative energy prices being continued to 2030 .

Price elasticity of energy demand. The question of the price elasticity of energy demand is an important and a vexed one. Estimating the price elasticity of demand is especially difficult when, as in China during much of the period from 1980 to 2005, real energy use was supply constrained and prices were partly responsive to the underlying supply-demand gap arising from supply constraints. In view of this fact, estimates of the price elasticity in China derived in the literature from demand equations estimated on historical data must be treated with caution for our purposes.

There is an extensive international literature on the estimation of energy price elasticities across countries. For example, Gately and Huntington (2002) found that the long-run price elasticity for the OECD region for 1971-97 was -0.24 , and -0.08 for 14 developing countries (not including China) with aboveaverage per capita income growth, with evidence in both cases of asymmetrical responses to rising and falling prices. Pesaran et al. (1998) found that the longrun elasticity was about -0.3 for 10 Asian countries (again, excluding China). For China, Fisher-Vanden et al. (2004) find an elasticity of -0.368 from their cross-sectional analysis of manufacturing firms in 1997-99; Shi and Polenske (2006) find a long-run price elasticity for the industrial sector of -0.78 for 1980-2002; Hang and Tu (2007) find an elasticity of -0.54 for $1985-95$ and of -0.65 for 1995-2005; while Chen et al. (2007) use a range of elasticities from -0.1 to -0.5 in their MARKAL model analysis. In the light of the international literature and concerns about estimating demand elasticities for China in a supply-constrained market, we use an elasticity of -0.4 for the energy-intensive industries and -0.2 for other industries.

Sectoral growth elasticities. At the aggregate level, the key variable is the rate of growth of industry value added (excluding construction) relative to the overall GDP growth rate. In 2006, and during 2001-06, growth in industry value added was 16 per cent greater than in GDP (elasticity of 1.16). It is assumed, in the base case, that the elasticity of the growth of industry relative to GDP falls to 1.05 by 2015 and then declines gradually to 1 by 2030 . Growth in agricultural value added is set at 40 per cent of GDP growth, and tertiary-sector growth is the residual. These assumptions imply a gradual retreat from industry-driven growth, with the growth in the tertiary sector exceeding that of industry after 


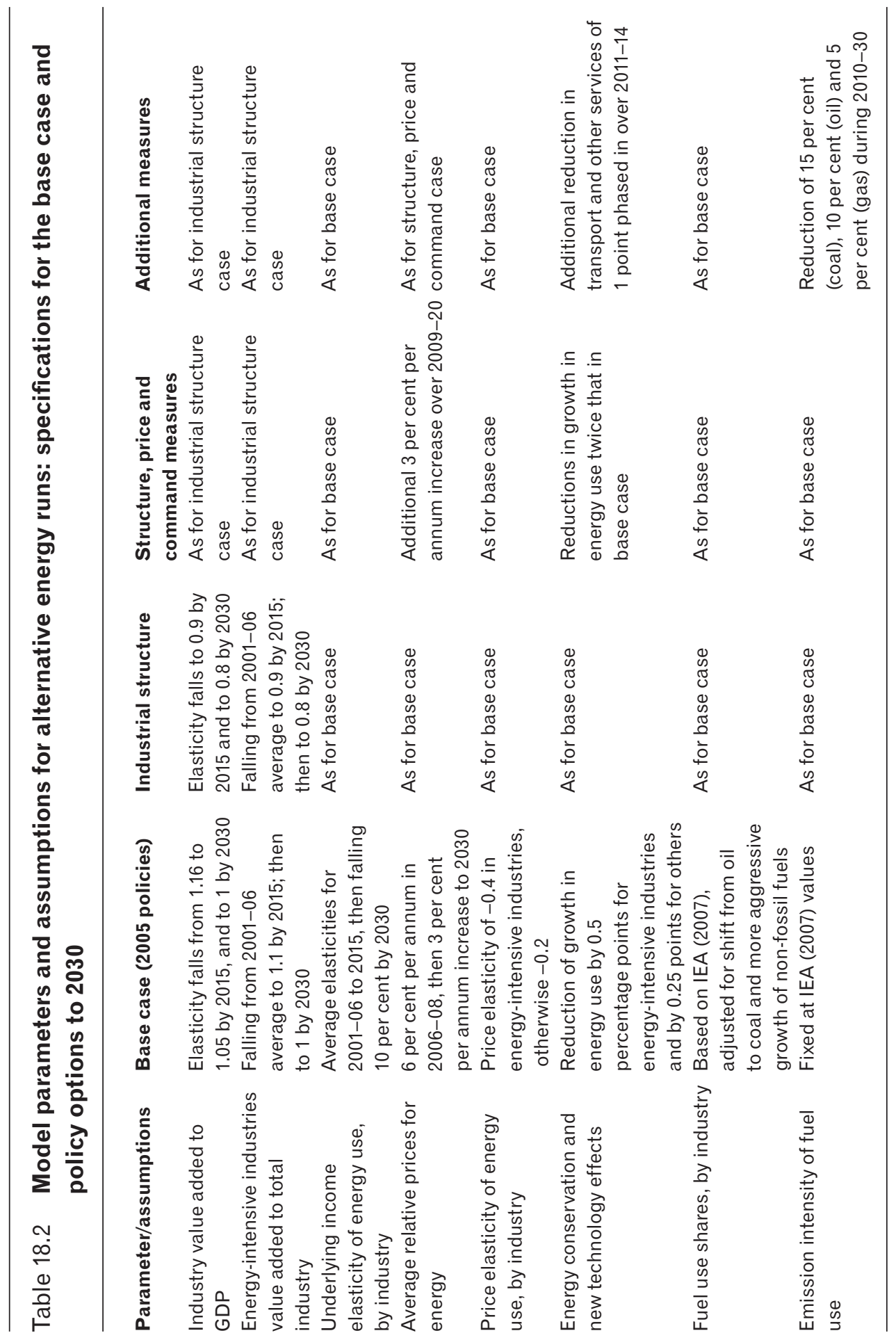


2015. The new industrial structure option involves a much more rapid move to a service-oriented economy, with the elasticity of industrial growth with respect to GDP being reduced rapidly to 0.9 by 2015 and to 0.8 by 2030 .

The sectoral growth elasticities relate to relative rates of growth within the industrial sector (excluding construction). For 2001-06, real value added in the five energy-intensive industries taken as a whole grew by 15.2 per cent in comparison with overall industrial growth of 11.7 per cent-implying a growth elasticity of 1.30. Growth patterns were, however, variable across the industries. For individual energy-intensive industries, the elasticities of growth relative to all industry are set initially at the average for 2001-06, bounded at 1.5 where the historical figure exceeds that level. In the base case, these elasticities are assumed to decline gradually to 1.1 by 2015 , and then to 1 by 2030. In the new industrial structure case, the pattern of change is more rapid, with the growth elasticities of these industries being reduced rapidly to 0.9 by 2015 and to 0.8 by 2030 . The combination of these two sets of assumptions is that, in this case, the structure of the Chinese economy changes profoundly in the next decade or so; by 2020 , the growth rate of the energy-intensive industries is only about 5 per cent in comparison with the assumed GDP growth rate of 7 per cent per annum at that time.

Technology and energy conservation policies. While there is clear evidence that, during the period of limited energy supplies and a command economy in the 1980s and 1990s, technology and energy conservation policies had a substantial impact on energy use, no quantitative measure of that impact is available. Some of the command and control measures that have recently been implemented in this area have been noted above. In the absence of more precise information, we assume that the more limited policies included in the base reduce energy use by 0.5 percentage points per annum in energy-intensive industries and by 0.25 points in other industries; and, in the price and command measures strategy, these effects are doubled in both industry types. Clearly, this is only a preliminary specification, and requires further work.

Fuel use by type and emissions intensities of fuel types. The values for China for the projection period of $s_{i j t}$, the industry-specific shares of various fuel types in total energy use, and of $m_{j t}$ the emissions intensity of different fuel types, are based on the values used in IEA (2007) - varying from those estimates only for fuel use by type, where later information and increased knowledge of the emerging energy-use path is available. Massive expansion of coal production and of coal-fired power stations has been under way in China in recent years, while there is clear evidence of fuel substitution away from oil and considerable attention being given to renewable energies and to nuclear 
energy. As the industry-specific fuel-use shares are held fixed but the pattern of value added shifts across different cases, the overall fuel-use shares also vary across the cases.

The IEA's projections of carbon dioxide emissions per unit of fuel type used are adopted in full, and held fixed for all scenarios, other than for the additional measures case. Here it is assumed that new technologies, such as advanced clean-coal generation methods and carbon geosequestration, are introduced gradually after 2010 and with increasing effect after 2020.

\section{Reducing energy use and emissions with continued rapid development}

The results of the model simulations with the four cases are summarised in Table 18.3 and Figure 18.2. In the base case, energy use is projected to increase by 6.5 per cent per annum during 2005-30 and emissions rise by 6.1 per cent to 6.8 giga-tonnes of carbon (GtC) by 2030. The main growth is in the period to 2015-with energy use growing by 7.7 per cent per annum and emissions by 7.6 per cent per annum during 2005-15-with annual emissions growth slowing to 5.1 per cent during 2015-30. Nevertheless, the scale of energy use and emissions implied in this projection is such as to have major implications for the environment within China, for the global climate and for world resource markets.

In the new industrial structure case, the growth of energy use and emissions slows, but only by about 0.5 per cent per annum. This is somewhat surprising in the light of the significant change in industrial structure that is assumed, but reflects the assumed continuing reductions in energy intensity in high energy-using industries (in the base case) and the importance of transport and the services sector (including households) in the longer term. The additional measures in the second alternative case-higher continuing increases in relative energy prices and more effective measures to increase efficiency and to support the use of new technologies-have more effect, reducing the rate of growth of emissions during 2015-30 to 3.3 per cent. Even these assumptions are not sufficient to approach stabilisation of emissions, because in this case the use of fossil fuels in the services sector is still growing strongly.

As a result, further measures to reduce energy use in transport and other services, together with gains from technologies that reduce the level of emissions per unit of fossil-fuel use, are necessary to make stabilisation of emissions achievable. In the additional measures case, emissions are held to $3.5 \mathrm{GtC}$ in 2030, little more than half that in the base case, and grow by only 1.6 


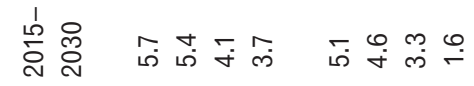

๙̊.

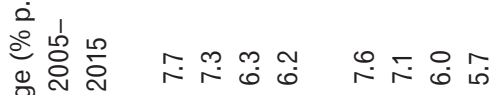
胥 $\frac{\pi}{0}$

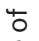

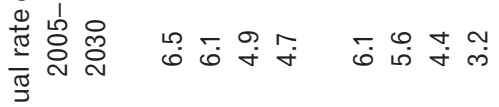
竞

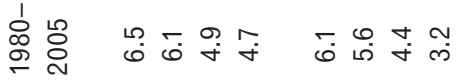

.

立 $\quad$ o

응

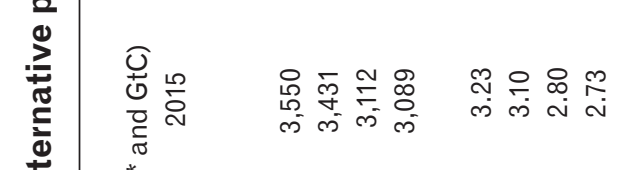

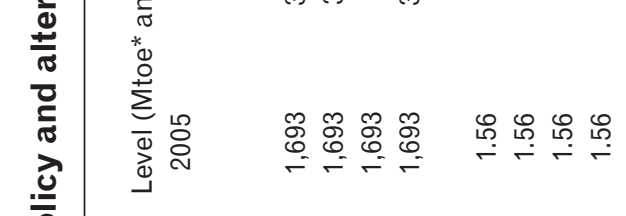

ำ

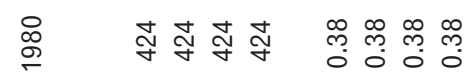


Figure 18.2 Carbon dioxide emissions from fuel combustion in China, 2005-30: the base case and alternative policy cases (GtC per annum)

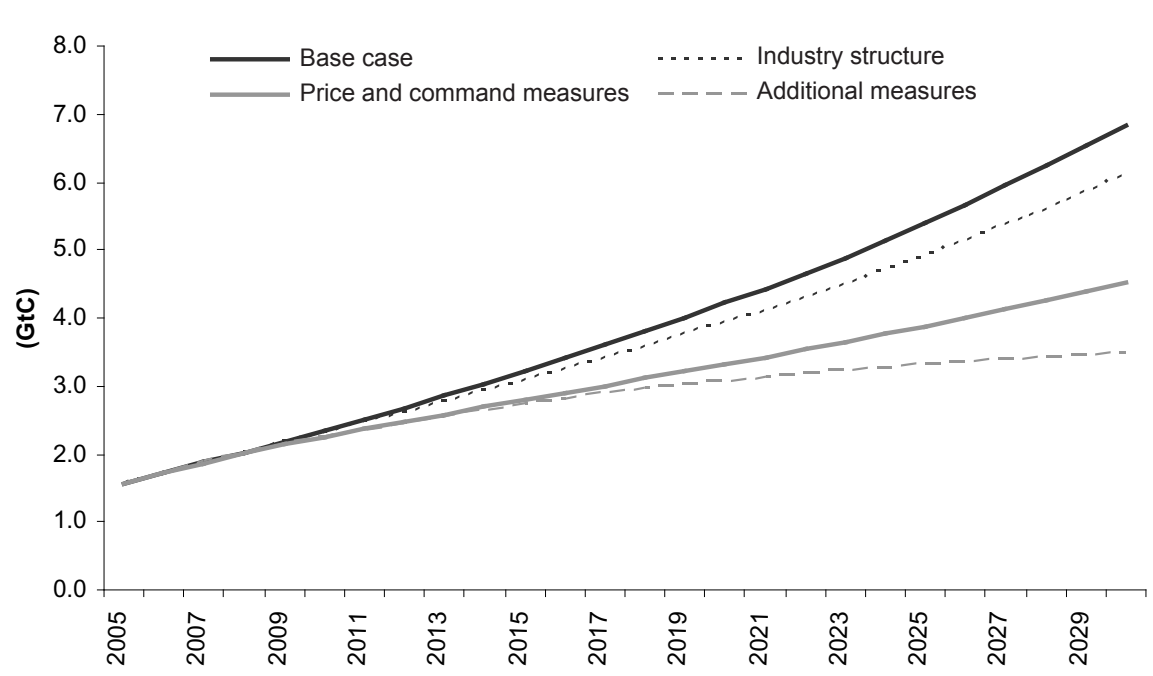

Source: Authors' estimates and IEA database.

per cent during 2015-30, with the annual growth rate approaching zero towards the end of the period. This is indeed a scenario in which emissions stabilise at less than $4 \mathrm{GtC}$ not long after 2030.

\section{Conclusion}

There are many uncertainties about China's future energy use, and about the effectiveness of the policies currently being discussed and implemented to curtail it. What is not uncertain is that it is in China's interest to curtail the rapid growth in energy use, and hence curtail the human and environmental costs that it creates, and such an outcome is highly desirable in terms of global climate outcomes. Can this be achieved while continuing rapid economic development, or must China choose between rapid growth and acceptable environmental outcomes?

This scoping study offers only limited evidence about the answer to this question, but it does point to several tentative conclusions. First, there might be realistic options in which China does not have to choose; these forms of 
implementation of the alternative development path sketched in the eleventh Five-Year Plan certainly deserve further study. Second, such a task will be difficult, and will require extensive and sustained policy initiatives in each of the six policy areas discussed here. Finally, achieving such an outcome seems clearly to be in the interests of the Chinese people and the international community, so that strong measures by governments of industrialised countries to support this policy implementation process in China would be well justified.

\section{Notes}

1 For example, for eight countries in South East Asia (excluding China), the unweighted mean elasticity of energy use with respect to GDP for the period 1971-2002 was 1.12, while for another 61 developing countries for which data were available the unweighted mean elasticity during this period was 1.45 (IEA 2006b). These figures exclude traditional biomass energy, as do the figures used for China.

\section{References}

Andrews-Speed, P., 2004. Energy Policy and Regulation in China, Kluwer Law International, The Hague.

Central Government Portal, 2007. A total of 41.67 million tons of the steel production capacities with backward technologies in ten regions will be dumped, Beijing. Available from http://www.gov.cn/jrzg/2007-05/15/ content_614511.htm

Chen, W., Wu, Z., He, J., Gao, P. and Xu, S., 2007. 'Carbon emission control strategies for China: a comparative study with partial and general equilibrium versions of the China MARKAL model', Energy, 32:59-72.

Clarke, L., Edmonds, J., Jacoby, H., Pitcher, H., Reilly, J. and Richels, R., 2007. Scenarios of greenhouse gas emissions and atmospheric concentrations, SubReport 2.1A of Synthesis and Assessment Product 2.1, US Climate Change Science Program and the Subcommittee on Global Change Research, Department of Energy, Office of Biological and Environmental Research, Washington, DC.

Fisher-Vanden, K., Jefferson, G.H., Hongmei, L. and Quan, T., 2004. 'What is driving China's decline in energy intensity?', Resource and Energy Economics, 26:77-97.

Garbaccio, R.F., Ho, M.S. and Jorgenson, D.W., 1999. 'Why has the energy-output ratio fallen in China?', Energy Journal, 20(3):63-91.

Gately, D. and Huntington, H.G., 2002. 'The asymmetric effects of changes in price and income on energy and oil demand', Energy Journal, 23(1):19-55. 
Hang, L. and Tu, M. 2007. 'The impacts of energy prices on energy intensity: evidence from China', Energy Policy, 35:2978-88.

Huang, J., 1993. 'Industry energy use and structural change: a case study of the People's Republic of China', Energy Economics, 15(2):131-6.

International Energy Agency (IEA), 2006a. World Energy Outlook 2006, International Energy Agency, Paris.

__, 2006b. World Energy Statistics and Balances, International Energy Agency, Paris.

—_, 2007. World Energy Outlook 2007, International Energy Agency, Paris.

International Monetary Fund (IMF), 2008. World Economic Outlook, International Monetary Fund, Washington, DC.

Lin, J., 2005. Trends in energy efficiency investments in China and the US, LBNL57691, Lawrence Berkeley National Laboratory, University of California, Berkeley, California.

Lin, X. and Polenske, K.R., 1995. 'Input-output anatomy of China's energy use changes in the 1980s', Economic Systems Research, 7(1):67-84.

Ministry of Finance (MOF), 2007. China will adjust the tariff rate for some of its tradable goods, 21 May, News Office, Ministry of Finance, Beijing. Available from ://www.mof.gov.cn/news/20070521_1500_26483.htm (accessed 11 June 2008).

National Bureau of Statistics (NBS), 2007. China Statistical Yearbook 2007, China Statistics Press, Beijing.

__- various years. China Statistical Yearbook, China Statistics Press, Beijing.

National Development and Reform Commission (NDRC), 2007. Urgent notice regarding the acceleration of industrial restructure and curbing the increasing expansion of high energy intensive industries, National Development and Reform Commission Document No.933, Beijing. Available from http://www. ndrc.gov.cn/zcfb/zcfbtz/2007tongzhi/t20070525_137359.htm (accessed 11 June 2008).

Naughton, B., 2006. The Chinese Economy: transitions and growth, MIT Press, Boston, Mass.

Pesaran, M.H., Smith, R.P. and Akiyama, T., 1998. Energy Demand in Asian Developing Economies, Oxford University Press, New York.

Sheehan, P. and Sun, F., 2007. Energy use and $\mathrm{CO}_{2}$ emissions in China: interpreting changing trends and future directions, CSES Climate Change Working Paper No.13, Centre for Strategic Economic Studies, Victoria University, Melbourne.

Sheehan, P. (forthcoming). 'The new global growth path: implications for climate change analysis and policy', Climatic Change. 
Shi, X. and Polenske, K.R., 2006. Energy prices and energy intensity in China: a structural decomposition analysis and econometrics study, Working Paper No.0606, Center for Energy and Environmental Policy Research, Massachusetts Institute of Technology, Cambridge, Mass.

Sinton, J.E. and Levine, M.D., 1994. 'Changing energy intensity in Chinese industry: the relative importance of structural shift and intensity change', Energy Policy, 17:239-55.

Sinton, J.E., Levine, M.D. and Qingyi, W., 1998. 'Energy efficiency in China: accomplishments and challenges', Energy Policy, 26(11):813-29.

Wen, J., 2006. Report on the work of the government 2006, Delivered at the Fourth Session of the Tenth National People's Congress, 5 March 2006, Beijing, People's Republic of China. Available from http://english.gov.cn/ official/2006-03/14/content_227248.htm (accessed 11 June 2008).

Weyant, J.P., de la Chesnaye, F.C. and Blanford, G., 2006. 'Overview of EMF-21: multi-gas mitigation and climate change', Energy Journal. Special Issue Multi-Greenhouse Gas Mitigation, 27:1-32.

World Bank, 2007. 2005 International Comparison Program: tables of final results, World Bank, Washington, DC. Available from http://siteresources.worldbank. org/ICPINT/Resources/ICP_final-results.pdf (accessed 11 June 2008).

\section{Acknowledgements}

The authors gratefully acknowledge the exceptional research support provided by Alison Welsh, Stephen Parker and Margarita Kumnick, and funding from the Australian Research Council under a Linkage Grant and from the industry partners to that grant. 